\title{
Pulmonary Toxicity Following Exposure to Waterproofing Grout Sealer
}

\author{
G. Patrick Daubert, MDa, Henry A. Spiller, MS ${ }^{b}$, Barbara Insley Crouch, PharmD ${ }^{c}$, \\ Steven A. Seifert ${ }^{a}, M D^{d}$, Karen E. Simone, PharmD, Susan C. Smolinske, PharmDf
}

\author{
aDepartment of Emergency Medicine, University of California, Davis, Medical Center, Sacramento Division, California Poison \\ Control System \\ bKentucky Regional Poison Center, Louisville, KY \\ cUtah Poison Control Center, and Department of Pharmacotherapy, University of Utah, Salt Lake City, UT \\ dNew Mexico Regional Poison Control Center, Albuquerque, NM \\ eNorthern New England Poison Center, Portland, ME \\ fDepartment of Emergency Medicine and Pediatrics , Children's Hospital of Michigan Regional Poison Control Center, \\ Wayne State University School of Medicine, Detroit, MI
}

\begin{abstract}
Introduction: We report a large number of cases of pulmonary toxicity from 6 regional poison control centers associated with the use of a waterproofing-grout sealer. The identification of this illness occurred by means of the poison control center (PCC) national automated toxicosurveillance.

Materials and Methods: This is a retrospective case review of all cases of pulmonary toxicity following exposure to a waterproofing grout sealer from 6 regional PCCs including Michigan, Kentucky, Utah, Maine, Arizona, and Nebraska. The study period extended from June 1, 2005 to December 1, 2005.

Results: The vast majority of patients used the product at home (80\%). Over half the patients presented within 3 hours of exposure. The most common presenting symptoms were shortness of breath (63\%), cough (60\%), and chest pain (44\%). Wheezing (33\%) and rales (23\%) were the most common signs of clinical toxicity. One patient required endotracheal intubation. Thirty-seven percent of patients had signs of acute pneumonitis on initial chest x-ray. The mean presenting oxygen saturation was $89.5 \%$. The most common treatment measures used were supplemental oxygen, bronchodilator therapy, oral steroids, and antibiotics. Over half of the study group required hospital admission.

Conclusion: The majority of patients in this study were adults using the product at home. Over one-third of patients had an abnormal x-ray upon presentation. Over half of the study group required hospital admission following exposure to this product. Medical professionals should be aware of the potential for pulmonary toxicity due to waterproofing aerosols.
\end{abstract}

Keywords: pneumonitis, Stand'n Seal Grout Sealer, fluoropolymer, waterproofing aerosol, toxicity

Acknowledgments: The authors thank the staff from the regional poison control centers of Michigan, Kentucky, Utah, Arizona, Maine, and Nebraska for assisting with the follow-up of patients in this case series.

Notes: This research was presented in abstract form at the 2006 NACCT meeting: Daubert GP, Spiller H, Smolinske S. Pulmonary Toxicity Following Exposure to Waterproofing Grout Sealer. Clin Toxicol. 2006;44:608.

There was no outside funding of any kind used for this study.

Corresponding author: G. Patrick Daubert, MD, Department of Emergency Medicine, University of California Davis Medical Center, 4150 V Street, PSSB Suite 2100, Sacramento, CA 95817. Email: patrick.daubert@ucdmc.ucdavis.edu 


\section{INTRODUCTION}

In March 2003, all poison centers became a part of a nationwide automated toxicosurveillance system. The American Association of Poison Control Centers (AAPCC) National Poison Data System (NPDS, previously Toxic Exposure Surveillance System (TESS)) toxicosurveillance system enables poison control centers (PCCs) to recognize a potentially hazardous product by identifying similar clinical symptoms in separate cases. There are 131 possible signs or symptoms that can be used to code a clinical illness in any case reported to a center. When similar signs or symptoms recur, a "spike" is identified. Recently, an additional feature was incorporated into this system that generates emails to center directors based on clinical symptoms. It was this system and its features that made it possible to detect a cluster of human illness associated with the use of a certain product.

We report 30 cases of pulmonary toxicity from 6 regional PCCs associated with the use of Tile Perfect Stand'n Seal "SprayOn" Grout Sealer (Stand'n Seal). This water-repellent aerosol is similar in composition, but not in usage, to those previously reported to cause chemical pneumonitis. A review of the current literature regarding the toxicity of waterproofing aerosols is also presented.

\section{MATERIALS AND METHODS}

This is a retrospective review of cases of pulmonary toxicity following exposure to Stand'n Seal Tile and Grout Sealer (Stand'n Seal) from 6 regional PCCs, including Michigan, Kentucky, Utah, Maine, Arizona, and Nebraska. Cases were identified and prospectively analyzed between June 1, 2005 and December 1, 2005. Stand'n Seal cases were originally identified as a spike in "dyspnea" using the toxicosurveillance system. The initial spike generated by the toxicosurveillance system led to the current investigation in this study group. Further review of these cases revealed pneumonitis-related symptoms, and collaboration between poison centers revealed that a single product was responsible. The study group was comprised of all patients with symptoms temporally related to the use of Stand'n Seal as identified by the toxicosurveillance system. Data collected included age, gender, location of exposure (home or work), presenting complaint, presenting signs of toxicity, chest radiograph findings, pulse oximetry, treatment, and final disposition from the emergency department (ED). Patients were included in the analysis if there was a history of an acute exposure to Stand'n Seal and the patient was treated at a healthcare facility. Cases were excluded if there was no treatment at a healthcare facility or the call was for information only (i.e., no exposure). Lot numbers were not originally recorded during patient presentation and chart development, but were obtained when possible following the voluntary recall of Stand'n Seal on August 31, 2005. The study was approved by the Wayne State University Human Investigational Committee.

\section{RESULTS}

A total of 40 cases were identified from 6 different regional PCCs. Thirty cases met inclusion criteria. Six cases involved a single family treated at home (no healthcare facility involvement) and 4 cases were informational calls with no documented exposure. There was no objective verification of symptoms in the 6 patients treated at home. Therefore, the remaining description of clinical effects and outcomes includes only those 30 patients seen in the hospital. Table 1 describes the demographics and presenting characteristics of the study group.

The majority of cases involved adults, with a mean age of 38 years. There was one pediatric exposure (10 years old). The vast majority of patients used the product at home (92\%). Over half of the patients (54\%) presented within 1 hour of exposure. The most common presenting symptoms were shortness of breath (63\%), cough $(60 \%)$, chest pain (43\%), nausea/vomiting (33\%), and headache (20\%). Wheezing (33\%) and rales (23\%) were the most common signs of clinical toxicity, followed by tachycardia (23\%) and tachypnea (20\%). The mean presenting oxygen saturation on room air was $89.5 \%$ with a range of $79-98 \%$. Over $43 \%$ of patients were noted to have a presenting pulse oximetry reading of $<90 \%$ on room air. Approximately $37 \%$ of the patients were noted to have pulmonary infiltrates on initial chest radiograph. Over half of the patients (53\%) presenting to a hospital required admission, while $37 \%$ were discharged home after initial treatment at a healthcare facility. In $10 \%$ of patients the final disposition was not known. One patient, with a presenting pulse oximetry reading of $84 \%$, required endotracheal intubation. Table 2 describes the treatment patients of the study group. Treatment regimens most commonly consisted of supplemental oxygen, bronchodilator therapy, oral steroids, and antibiotics. Eight cases of pulmonary toxicity from Stand'n Seal presented after the recall date of August 31, 2005. Six of these cases included lot numbers that were not involved in the original product recall.

\section{DISCUSSION}

Aerosolized water repellents have three primary components: a propellant, an organic or nonorganic solvent, and a waterrepelling agent. Propellants are often short-chain hydrocarbons, such as butane or propane. Some aerosols also use carbon dioxide. Among the solvents typically used are petroleum distillates (heptane), acetates, methylethyl ketone, and previously 1,1,1trichloroethane (TCE). The water-repelling agent used is typically a fluoropolymer resin, a silicon-based resin, or a combination of both.

Due to changes in federal regulation in the early 1990s, the chemical composition of many of these aerosols changed significantly. The Clean Air Act amendments of 1990 (effective January 1994) prohibited the sale or distribution of products containing TCE [1]. Prior to 1990, manufacturers of water-repellent aerosols widely used TCE as a solvent and with this new regulation were forced to modify their formulations. Previously used 
Table 1: Characteristics of Patients Exposed to Stand'n Seal Grout Sealer§

\begin{tabular}{|c|c|}
\hline Patient Characteristics & n (\%) \\
\hline Male & $18(60 \%)$ \\
\hline \multicolumn{2}{|l|}{ Location } \\
\hline Home & $24(80 \%)$ \\
\hline Work & $2(7 \%)$ \\
\hline Unknown & $4(13 \%)$ \\
\hline \multicolumn{2}{|l|}{ Presenting complaint } \\
\hline Shortness of breath & $19(63 \%)$ \\
\hline Cough & $18(60 \%)$ \\
\hline Chest tightness/pain & $13(43 \%)$ \\
\hline Nausea/vomiting & $10(33 \%)$ \\
\hline Headache & $6(20 \%)$ \\
\hline Throat pain & $3(10 \%)$ \\
\hline Lightheaded/dizziness & $3(10 \%)$ \\
\hline Unknown & $2(7 \%)$ \\
\hline
\end{tabular}

Presenting sign

\begin{tabular}{lc}
\hline Wheezing & $10(33 \%)$ \\
\hline Crackles & $7(23 \%)$ \\
\hline Tachycardia & $7(23 \%)$ \\
\hline Tachypnea & $6(20 \%)$ \\
\hline Fever & $2(7 \%)$ \\
\hline Leukocytosis & $3(10 \%)$ \\
\hline Unknown & $11(36 \%)$ \\
\hline
\end{tabular}

Pulse oximetry

\begin{tabular}{ll} 
Mean & $89.5 \%$ \\
\hline Patients $\leq 90 \%$ on room air & $13(43 \%)$ \\
\hline Unknown & $8(27 \%)$
\end{tabular}

Chest radiograph findings

\begin{tabular}{ll} 
Normal & $12(40 \%)$ \\
\hline Bilateral infiltrates & $9(30 \%)$ \\
\hline Unilateral infiltrate & $2(7 \%)$ \\
\hline Unknown & $7(23 \%)$ \\
\hline
\end{tabular}

Exposure to product

\begin{tabular}{lc}
\hline Exposed prerecall & $22(53 \%)$ \\
\hline Exposed postrecall & $8(27 \%)$ \\
\hline Lot numbers not in recall & $6(20 \%)$ \\
\hline
\end{tabular}

$\S$ Total numbers of patients in study $=30$

$W B C$, white blood cell count in cells $/ \mathrm{mm}^{3} ; \mathrm{CXR}$, chest radiograph
Table 2: Treatment and Disposition of Patients Presenting with Pulmonary Toxicity from Stand'n Seal Grout Sealer

\begin{tabular}{lc}
\hline Patient Characteristics & $\mathbf{n}(\mathbf{\%})$ \\
\hline Treatment & $1(3 \%)$ \\
\hline Endotracheal intubation & $28(93 \%)$ \\
\hline Oxygen & $24(80 \%)$ \\
\hline Bronchodilators & $9(30 \%)$ \\
\hline Steroids & $3(10 \%)$ \\
\hline Antibiotics & $1(3 \%)$ \\
\hline Antihistamine & $1(3 \%)$ \\
\hline Magnesium sulfate & $2(7 \%)$ \\
\hline Unknown & \\
\hline Disposition & $11(37 \%)$ \\
\hline Discharged same day & $16(53 \%)$ \\
\hline Required hospital admission & $3(10 \%)$ \\
\hline Unknown & \\
\hline
\end{tabular}

fluoropolymer resins were poorly soluble in the new solvents. Therefore, the fluoropolymer resins were modified to increase their solubility. The occurrence of pulmonary toxicity observed in this study may be related to these changes in formulation.

A number of cases of chemical pneumonitis have occurred following the use of waterproofing aerosols [2-8,10-12]. A study in female mice of the effects of inhalation of fluoropolymer and silicone resins, heptane, ethyl acetate, and resin-free mixtures demonstrated histopathological changes of atelactatic alveoli and alveolar wall hyperemia in response to the fluoropolymer [13]. Heptane and ethyl acetate alone did not cause significant changes on lung pathology when compared to controls. In addition, silicon-based resins did not contribute to significant lung pathology, whereas fluoropolymer resins demonstrated remarkable lung pathology. The authors concluded that the fluoropolymer resin was etiologically involved in the respiratory disorder caused by inhalation of waterproofing sprays.

There is a common theme among case presentations of people exposed to aerosolized water repellents. Patients develop early, rapid symptoms consisting primarily of cough, shortness of breath, and occasionally chest pain. All products linked to an acute respiratory illness have contained a fluoropolymer resin. It remains unclear if changes in the solvent content also contribute to the pulmonary symptoms.

Stand'n Seal is a waterproofing aerosol containing a noxious stimulant (N-butyl acetate), the propellants isobutane and propane, C8-C9 petroleum hydrocarbon solvents, and a fluoropolymer resin. It is employed as an aerosol both commercially and privately to seal tile and grout surfaces. As of August 31, 2005, 
there were 88 reported cases of adverse reactions to Stand'n Seal, with 28 confirmed reports of pulmonary toxicity requiring medical attention [9]. Stand'n Seal underwent a voluntary recall coordinated by the U.S. Consumer Product Safety Commission (CPSC) in August of 2005. A select number of lot codes were identified at that time as products linked to the respiratory illness. It was believed that the concentration of N-butyl acetate was not high enough (noxious stimulus) to induce consumers to minimize their exposure to the aerosol fumes [9]. Nonetheless, a significant number of cases occurred after the recall date with lot numbers not originally identified.

In our current study we identified 30 cases of pulmonary toxicity related to acute exposure to Stand'n Seal requiring initial treatment in a healthcare facility. The majority of patients were adult males using the product at home. Most patients developed symptoms within 3 hours of exposure. All patients in this study group used the product in a small, enclosed space with inadequate ventilation and little or no personal protective equipment (PPE). Nearly two-thirds of patients complained of either shortness of breath or cough. Almost half of the patients presented with a pulse oximetry reading of $<90 \%$ on room air. A significant portion $(60 \%)$ of patients who presented within an hour of symptom onset had a positive chest radiograph. It is not clear if the early findings on chest radiograph represent the actual fluoropolymer compound, early lung injury, or a combination of both. Although only 3 patients had laboratory studies available for evaluation, all 3 had white blood cell counts $>19,000$ cells $/ \mathrm{mm}^{3}$ with 1 patient developing a leukocyte count of 32,000 cells $/ \mathrm{mm}^{3}$ at the time of admission. Nearly half of the patients required hospital admission due to the severity of their illness. Patients presenting within 3 hours of exposure were more likely to require hospital admission than those presenting $>10$ hours after exposure (59\% vs. $43 \%$ ). Long-term outcome was not assessed in this study.

The exact mechanism of toxicity for Stand'n Seal and similar water repellent aerosols has not been determined. A number of etiologies may explain the pulmonary symptoms. First, the fluoropolymer may act as a carrier molecule allowing the hydrocarbon solvent to deeply penetrate alveoli [3]. Second, because of increased solvent volatility, the size of aerosol particles decreases more rapidly, resulting in increased inhalation and increased number of particles reaching the alveoli [7]. Third, the fluoropolymer resin may interact with type II alveolar cells and surfactant, generating acute lung injury [13].

A variety of public health and safety concerns came to light during the investigation of these cases. The product label did not contain adequate information regarding the product ingredients. In addition, the product's material safety data sheet (MSDS) contained an incomplete list of ingredients, failing to list the fluoropolymer resin. Furthermore, identifying the primary manufacturer of this product was challenging. There were several echelons of distributors that packaged and marketed the final product. Once reached, the manufacturer was reluctant to release specific information regarding active ingredients, desiring to protect proprietary information.

Limitations of this study include its retrospective design and missing data points. In addition, cases were originally identified based on the report of pulmonary symptoms (e.g., dyspnea). This reliance on reported symptoms may have resulted in a failure to detect some cases of toxicity. In addition, we were unable to obtain adequate information of the symptoms in the 6 patients treated at home in order to compare them to the 30 patients presenting to a healthcare facility. Although a temporal association exists between the use of Stand'n Seal and the development of pulmonary symptoms, the retrospective design prevents an evidence-based determination of causation. Finally, the presenting symptoms in this study population are found in innumerable other individuals on a daily basis, not related to any toxic exposure. Confounding clinical etiologies as well as dose issues were not addressed in this study group.

Linking pulmonary symptoms to Stand'n Seal was challenging. There were a number of companies involved in its manufacture and labeling. The MSDS did not list any ingredients comprising $<1 \%$ of the product's composition (i.e., the fluorocarbon). Finally, there was no single generic AAPCC category to enable searching TESS for similar commercial products. The absence of such a category precluded the ability to make an initial comparison between Stand'n Seal and other products similar in application or composition with respect to the prevalence of comparable clinical effects or medical outcomes associated with their use.

Stand'n Seal is a product used as a "grout sealant" and is not generally categorized with other "waterproofing" products. This limited the ability of regional PCCs to accurately identify cases. The increase in the number of patients with respiratory symptoms temporally related to the use of Stand'n Seal prompted the AAPCC to create a new category for waterproofing agents.

\section{CONCLUSION}

Pulmonary toxicity following exposure to waterproofing aerosols continues to occur. The exact mechanism of the toxicity has not yet been determined. Stand'n Seal and other waterproofing aerosols that contain fluoropolymer resins should be used only in adequately ventilated areas. Many of these products are marketed for home use and therefore create a hazard to the general public in non-occupational settings where the product may be used indoors, in poorly ventilated areas, and without PPE. The majority of patients report an abrupt onset of respiratory symptoms, with dry cough as a prominent feature. Patients presenting within an hour of exposure were more likely to have clinical symptoms and were more likely to be admitted to a hospital.

PCCs play an important sentinel role in detecting product formulation toxicity and/or need for improved labeling of consumer products. Many of these cases were initially diagnosed as routine allergic reactions or community-acquired pneumonia. The 
new automated, NPDS surveillance system provides additional capability to identify common etiological agents of toxicity presenting to emergency departments based on analysis of syndromes.

The authors have no potential financial conflicts of interest to report.

\section{REFERENCES}

1. Environmental Protection Agency [webpage on the Internet]. The Plain English Guide to the Clean Air Act. EPA-400-K93-001. April 1993. Available from: http://www.thecre.com/ fedlaw/legal14air/pegcaain.htm

2. Groot R. Sudden increase of acute respiratory illness using a spray product to waterproof clothing and shoes. I Toxicol Clin Toxicol 2003;42;443 (Abstract).

3. Heinzer R, Ribordy V, Kuzoe B, et al. Recurrence of acute respiratory failure following use of waterproofing sprays. Thorax 2004;59:541-542.

4. Ishizawa J, Tujikama A, Kuroki Y, et al. Acute poisoning of a waterproofing spray. Nihon-Ili-Shinpou (Jpn) 1994;3638:47-50.

5. Kelly K, Ruffing R. Acute eosinophilic pneumonia following intentional inhalation of Scotchguard®. Ann Allergy 1993;71:358-361.
6. Laliberté M, Sanfacone G, Blais R, et al. Acute pulmonary toxicity linked to use of a leather protector. Ann Emerg Med 1995;25:841-844.

7. Lazor-Blanchet C, Rusca S, Vernez D, et al. Acute pulmonary toxicity following occupational exposure to a floor stain protector in the building industry in Switzerland. Int Arch Occup Environ Health 2004;77:244-248.

8. Perrone H, Passero M. Hydrocarbon aerosol pneumonitis in an adult. Arch Intern Med 1983;143:1607-1608.

9. CPSC. Tile Perfect, Inc. Announce Recall of Stand'n Seal ${ }^{\mathrm{TM}}$ Grout Sealer Due to Respiratory Problems. U.S. Consumer Product. August 31, 2005. 2005; Release \#05-253.

10. Centers of Disease Control. Acute respiratory illness linked to the use of aerosol leather conditioner-Oregon, December 1992. MMWR Morb Mortal Wkly Rep 1993;41: 965-967.

11. Centers of Disease Control. Severe Acute Respiratory Illness Linked to Use of Shoe Sprays-Colorado, November 1993. MMWR Morb Mortal Wkly Rep 1993;42:885-887.

12. Burkhart KK, Brett A, Petrini G, et al. Pulmonary toxicity following exposure to an aerosolized leather protector. J Toxicol Clin Toxicol 1996;34:21-24.

13. Yamashita M, Tanaka J, Hirai H, et al. Pulmonary collapse and pneumonia due to inhalation of water-proofing aerosols in female CD-1 mice. J Toxicol Clin Toxicol 1995;33:631-637. 